\title{
PENETAPAN HARGA BERBASIS PENERIMAAN KONSUMEN DI DUAL-CHANNEL SUPPLY CHAIN
}

\author{
ERWIN WIDODO \\ Jurusan Teknik Industri, Institut Teknologi Sepuluh Nopember (ITS) Surabaya \\ Kampus ITS, Sukolilo, Surabaya 60111 \\ Surel: erwin@ie.its.ac.id
}

\begin{abstract}
ABSTRAK
Dual-Channel Supply Chain (DCSC) adalah sebuah struktur gabungan yang secara simultan memanfaatkan online dan offline channel untuk mendistribusikan sebuah produk. Struktur ini menjanjikan perluasan jangkauan pasar yang berujung pada peningkatan pendapatan. Meskipun demikian, selain menawarkan potensi, DCSC juga membawa beberapa problem. Salah satu problem yang dominan adalah penetapan harga harga antar channel. Pada prakteknya, para pelaku DCSC seringkali secara intuitif menetapkan harga online dan offline-nya. Belum ada sebuah mekanisme pengukuran yang representatif untuk problem yang sebenarnya sangat penting ini. Paper ini mencoba menjawab tantangan tersebut dengan mengusulkan sebuah mekanisme estimasi pengukuran secara kuantitatif tentang penerimaan pelanggan terhadap online channel relatif terhadap offline channel. Pendekatan yang diusulkan adalah pemanfaatan model matematis tentang hubungan interplay antar harga online dan offline. Parameter penting yang menjadi perhatian utama adalah sebuah rasio penerimaan pelanggan kepada online channel relatif terhadap offline channel. Parameter ini diukur dari 3 kelompok produk yang dijual dalam struktur DCSC yang ada di Indonesia guna menunjukkan perbedaan karakteristik dari masing-masing kelompok produk tersebut. Hasil percobaan numerik yang dilakukan menunjukkan bahwa pemanfaatan usulan mekanisme penetapan harga ini dapat meningkatkan performansi finansial DCSC amatan.
\end{abstract}

Kata kunci: dual-channel supply chain, penetapan harga, online channel, offline channel

\begin{abstract}
Dual-Channel Supply Chain (DCSC) is a mixed structure which simultaneously utilizes both offline and online channel to distribute one particular product or service. This structure provides market reach extension in which eventually leads to revenue increase. Whatsoever, aside of this advantage, DCSC also brings some challenging problems. One prominent problem is of about between-channel pricing-problem. In its practice, DCSC actors often apply intuitive offline and online pricing without further analytical evaluation. Yet there is no representative mechanism to address this critical problem. This paper attempts to resolute this challenge by proposing a qualitative estimation mechanism on customer acceptance on online channel relative to offline one. This proposed approach is about to utilize an interplay relationship between offline and online prices. The main parameter to consider is a ratio of customer acceptance parameters. These parameters are elicited from 3 groups of products which are sold under DCSC structure in Indonesian cases to exhibit the different properties in each product group. Numerical experiment result shows that the utilization of this pricing mechanism may increase the financial performance of DCSC under observation.
\end{abstract}

Key words: dual-channel supply chain, pricing, online channel, offline channel

\section{PENDAHULUAN}

Pemanfaatan internet yang semakin intensif, sebagaimana data yang disajikan oleh Asosiasi Penyelenggara Jasa Internet Indonesia (APJII) sebesar 82 juta orang di tahun 2013 dan diprediksikan akan menjadi 107 juta orang di tahun 2014 (www.apjii.or.id.), membawa banyak perubahan dalam perilaku bisnis distribusi produk dan jasa. Potensi pengguna internet yang semakin besar ini memunculkan ide penggunaan online channel pendistribusian produk dan jasa. Sebuah ide yang sedang banyak menyita perhatian 
para praktisi dan akademisi (Bernstein, 2008; Chu et al., 2013; Dumrongsiri et al., 2008; Mahar et al. 2009; Widodo et al., 2011; Xu et al., 2012; Yan, 2008) dalam konteks ini adalah Dual-Channel Supply Chain (untuk selanjutnya disingkat dengan DCSC). Secara skematis, definisi DCSC diilustrasikan pada Gambar 1 (bagian tengah). Terdapat sebuah supplier yang menyalurkan sebuah produk atau layanan tertentu kepada pelanggan. Supplier bekerja sama dengan store untuk memenuhi offline demand. Selanjutnya, jalur distribusi ini disebut sebagai offline channel. Sebagai penambahan, dengan memanfaatkan kelebihan fitur internet yang tembus batas ruang, supplier juga menambahkan fasilitas online untuk melayani online demand. Dua jenis channel ini secara bersamaan memenuhi permintaan pelanggan yang memiliki karakter cukup sensitif melakukan perpindahan channel dalam melakukan pembelian produk ataupun jasa yang ditawarkan. Beberapa perusahaan internasional telah memanfaatkan struktur DCSC ini antara lain IBM, Sony, Panasonic dan lain sebagainya. Beberapa megastore-pun, seperti WalMart, Barnes \& Noble juga menerapkan konsep ini. Sedangkan di Indonesia, implementasi supply chain secara simultan ini banyak dipakai untuk penjualan komoditas seperti buku, tiket pesawat, produk-produk apparel, peralatan elektronik, dan sebagainya. Sebagai data pendukung, Setyowati (2012) dalam penelitiannya menyebutkan bahwa berdasarkan data lembaga riset International Data Corporation (IDC), nilai transaksi online di Indonesia dalam tahun fiskal 2011 menyentuh angka Rp 30 triliun. Fakta ini mengindikasikan bahwa internet telah dimanfaatkan secara cukup intensif sebagai media komersial oleh para pelaku bisnis di Indonesia.

Potensi DCSC yang bisa meningkatkan penjualan dengan rata-rata $20 \%$ (Widodo et al., 2011) serta meraih pasar baru dengan memanfaatkan fitur internet secara signifikan ini menarik perhatian para peneliti untuk berkontribusi dalam pengembangan DCSC. Secara garis besar, kontribusi ini dapat dikelompokkan menjadi 2 golongan. Golongan

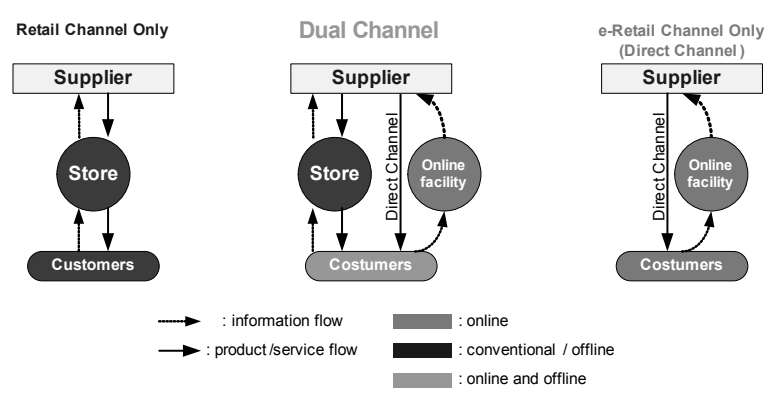

Gambar 1. Struktur DCSC Dibandingkan Retail Only (kiri) dan E-Retail Only (kanan)

pertama adalah pengembangan konseptual teoritis DCSC berkaitan dengan fase introduksi DCSC, disain network dan koordinasi antar channel (Mols, 2000; Gabrielsson et al., 2002; Steinfield et al., 2002).

Golongan kedua adalah pengembangan pada aspek-aspek tertentu agar secara praktis DCSC mampu diterapkan secara lebih efektif dan efisien. Tinjauan terhadap pricing strategy, inventory decision, customer behavior exploration, advertisement, dan lain sebagainya (Liu et al., 2013; Takahashi et al., 2011; Xu et al., 2012) adalah contoh-contoh kontribusi praktis dari para peneliti untuk pengembangan DCSC. Mols (2000) adalah salah seorang yang pertama kali merumuskan konsep DCSC. Di dalam papernya, Mols menunjukkan definisi, keuntungan dan hambatan implementasi penjualan offline dan online secara bersamaan. Secara mayoritas, peneliti DCSC berpijak pada konsep dasar yang diuraikan di paper ini. Sejak publikasi oleh Mols (2000), beberapa penulis lain mulai ikut berkontribusi dalam proses refining konsepsi DCSC. Dalam kelompok kontribusi untuk DCSC yang sama, yakni kelompok konseptual, Gabrielsson et al. (2002) melakukan analisis studi kasus terhadap channel penjualan personal computer (PC) di Eropa dengan memanfaatkan strategi multi-channel. Hasil yang didapat adalah terdapat potensi peningkatan profitabilitas apabila struktur jaringan pemasaran dirancang secara representatif sesuai karakteristik pasar yang dituju. Paper oleh Gabrielsson (2002) ini adalah sebuah contoh penajaman konsep 
DCSC dengan memanfaatkan sudut pandang marketing. Lebih jauh, paper oleh Gabrielsson juga mengambil sebuah kasus nyata penjualan produk yang tangible dalam struktur DCSC. Dalam waktu yang hampir bersamaan, Steinfield et al. (2002) mengusulkan secara eksplisit sebuah kerangka kerja konseptual yang mereka nyatakan dapat menjamin kesuksesan implementasi DCSC. Dengan memanfaatkan sebuah studi kasus, paper ini berhasil menunjukkan 4 manfaat DCSC, yakni penghematan biaya, peningkatan diferensiasi, memperkuat kepercayaan pelanggan dan ekstensi pasar.

Dari kelompok kontribusi aspek praktis atau implementasi DCSC, sebuah paper dari Takahashi et al. (2011) tentang pentingnya peranan biaya setup untuk pengelolaan persediaan dalam struktur DCSC dapat dipilih sebagai sebuah representasi. Dalam penelitian ini para penulis menyusun model stokastik dengan dasar proses Markov untuk merepresentasikan persediaan di DCSC. Berdasarkan model yang dikembangkan, penulis dapat menunjukkan signifikansi peranan biaya setup di dalam proses minimasi biaya persediaan DCSC. Selain itu, Xu et al. (2012) juga memberikan kontribusi untuk proses operasional DCSC berkaitan dengan penetapan harga dengan mempertimbangkan lead time yang terjadi di online channel. Sebagaimana diketahui, salah satu hambatan proses penjualan secara online adalah adanya konsekuensi lead time di mana untuk penjualan offline nilai lead time adalah nol atau mendekati nol. Dengan menggunakan model matematis, penulis dapat menunjukkan sensitivitas online pricing terhadap nilai lead time yang harus ditanggung oleh online customer. Sebuah contoh kontribusi operasional lainnya adalah paper tentang advertisement untuk DCSC yang ditulis oleh Liu et al. (2013). Penulis melibatkan biaya periklanan sebagai salah satu komponen yang harus diperhitungkan dalam keputusan penetapan harga, baik untuk channel online maupun offline. Hasil yang diperoleh adalah dengan mempertimbangkan biaya periklanan serta pengaruhnya terhadap penjualan, para pelaku DCSC dapat melakukan penetapan harga secara lebih akurat. Selain itu aktivitas periklanan dapat diukur efektivitasnya dengan melihat besaran demand yang diterima oleh dua belah channel, yakni online dan offline.

Meskipun telah banyak kontribusi secara konseptual maupun analitis matematis yang telah diberikan oleh para peneliti DCSC, penulis masih melihat gap terkait dengan aspek operasional penentuan harga dalam struktur DCSC. Terutama untuk problematika DCSC pricing di Indonesia, pendekatan yang bersifat intuitif masih sangat dominan dalam rangka membedakan besaran harga online dan offline untuk sebuah produk atau jasa yang sama. Hal ini muncul dikarenakan belum adanya sebuah mekanisme atau pendekatan secara sistematis kuantitatif yang dapat memberikan solusi riil terhadap keputusan penetapan harga di DCSC ini. Penelitian ini mengusulkan sebuah mekanisme penentuan harga online dan offline dengan berdasarkan sebuah terminologi spesifik yang ada di DCSC, yakni penerimaan pelanggan terhadap online channel relatif terhadap offline channel. Angka ini adalah sebuah perception value yang ada di benak pelanggan yang mana besar kecilnya akan menentukan pilihan channel seorang pelanggan. Dengan membangun sebuah model matematika, dibuatlah representasi keterkaitan antara harga online, offline dan parameter penerimaan pelanggan terhadap online channel ini terhadap demand, baik itu offline maupun online. Berdasar pada model offline dan online demand ini, dapat disusun satu model set optimasi pendapatan berdasarkan fungsi demand dan marginal profit yang ada di kedua channel. Selanjutnya, proses optimasi akan menghasilkan nilai harga offline dan online yang akan memberikan keuntungan optimum kepada masing-masing channel maupun DCSC secara keseluruhan.

Penelitian ini bertujuan menentukan komposisi harga offline dan online yang optimal, sehingga mampu memberikan performansi finansial yang lebih baik daripada penetapan harga offline dan online secara intuitif yang selama ini banyak dilakukan oleh penggiat 
DCSC. Agar mendekatkan dengan kasus nyata di Indonesia, penelitian dilakukan pada 3 kelompok produk yang banyak dijual dengan memanfaatkan struktur DCSC, yakni ticket, smartphone, dan produk fashion. Masing-masing kelompok produk tersebut mewakili high, medium dan low-level penerimaan pelanggan terhadap online channel. Dengan mengamati ketiga kelompok ini, penelitian ini akan menghasilkan sebuah spectrum, tidak hanya sebuah titik taksiran, terhadap nilai penerimaan pelanggan terhadap online channel. Berbekal kumpulan threshold values yang ditunjukkan dalam spectrum parameter penerimaan pelanggan terhadap online channel dalam penelitian ini, diharapkan para manager di DCSC memiliki pegangan yang objektif di dalam melakukan pengambilan keputusan penetapan harga. Dampak positif yang diharapkan adalah adanya peningkatan profit baik secara individu di offline dan online channel, serta DCSC secara keseluruhan.

\section{Penyusunan model}

Komponen dasar penyusunan model yang dipakai dalam penelitian ini adalah fungsi offline dan online demand pada Widodo et al. (2011). Fungsi offline demand diberikan oleh persamaan 1.

$\mathrm{D}_{\mathrm{s}}=d^{\text {max }}-\frac{\beta_{1}\left(\mathrm{P}_{\mathrm{s}}-\mathrm{P}_{\mathrm{o}}\right)}{1-\rho}$

Nilai offline demand $\left(\mathrm{D}_{\mathrm{s}}\right)$ dipengaruhi oleh permintaan maksimum terhadap sebuah produk/jasa tertentu ( $\left.d^{\max }\right)$, offline price $\mathrm{P}_{\mathrm{s}}$, online price $\left(\mathrm{P}_{\mathrm{o}}\right)$, faktor konversi dari harga menjadi kuantitas/demand offline $\left(\beta_{1}\right)$, dan $\rho$. Parameter $\rho$ menyatakan penerimaan pelanggan terhadap online channel relatif terhadap offline channel. Sebagaimana parameter komparatif pada umumnya, nilai interval untuk parameter ini adalah $0 \leq \rho \leq 1$.

Makna dari persamaan 1 adalah adanya sebuah hubungan yang bertolak belakang antara kenaikan $\mathrm{P}_{\mathrm{s}}$ dengan besaran $\mathrm{D}_{\mathrm{s}}$. Hal ini berarti semakin tinggi offline price yang ditawarkan, maka semakin rendah pula offline demand yang terjadi. Terkhusus pada item pengurang $\left(d^{\text {max }}\right)$, terdapat bagian pembilang $\left(\mathrm{P}_{\mathrm{s}}-\mathrm{P}_{\mathrm{o}}\right)$ yang merupakan manfaat penghematan yang dapat dilakukan pelanggan dan penyebut (1- $\rho$ ) yang menyatakan tingkat pengorbanan yang harus diterima oleh online customer dikarenakan tidak adanya inspeksi fisik dan excitement sebelum membeli sebagai pengorbanan pelanggan dalam membeli produk.

Fungsi online demand diberikan oleh persamaan 2 .

$\mathrm{D}_{\mathrm{o}}=\frac{\beta_{2}\left(\rho \mathrm{P}_{\mathrm{s}}-\mathrm{P}_{\mathrm{o}}\right)}{\rho(1-\rho)}$

Fungsi ini didapat dengan mengurangkan fungsi demand sebelum channel online dilibatkan dengan fungsi demand offline setelah online channel dilibatkan. Parameter $\beta_{2}$ adalah faktor konversi dari harga menjadi kuantitas/demand online.

Berdasarkan persamaan 1 dan 2 selanjutnya dapat disusun fungsi objektif untuk setiap channel dan DCSC secara keseluruhan. Dalam perspektif teori permainan, offline channel diposisikan sebagai follower, dan sebaliknya online channel selaku kepanjangan tangan dari supplier, berperan sebagai leader. Struktur kepemimpinan seperti ini dinyatakan sebagai Stackelberg leadership.

Fungsi objektif keuntungan offline channel $\left(\mathrm{G}_{\mathrm{s}}\right)$ sebagai follower dinyatakan oleh persamaan 3 .

$\max _{\mathbf{P}_{\mathrm{s}}} \mathbf{G}_{\mathrm{s}}=\left(\mathbf{d}^{\max }-\frac{\beta_{1}\left(\mathbf{P}_{\mathrm{s}}-\mathbf{P}_{\mathbf{o}}\right)}{1-\rho}\right)\left(\mathbf{P}_{\mathrm{s}}-\mathbf{P}_{\mathrm{w}}\right)$

Sedangkan fungsi objektif keuntungan online channel $\left(\mathrm{G}_{\mathrm{o}}\right)$ selaku leader dinyatakan oleh persamaan 4 .

$\max _{\mathbf{P}_{\mathrm{o}}} \mathbf{G}_{\mathbf{o}}=\left(\frac{\beta_{2}\left(\rho \mathbf{P}_{\mathbf{s}}-\mathbf{P}_{\mathbf{o}}\right)}{\rho(\mathbf{1}-\rho)}\right)\left(\mathbf{P}_{\mathbf{o}}-\mathbf{P}_{\mathrm{w}}\right)$

Sebagai supplier untuk offline dan online channel, keuntungan supplier $\left(\mathrm{G}_{\mathrm{w}}\right)$ dinyatakan oleh persamaan 5 .

$$
\begin{aligned}
& \max _{\mathrm{P}} \mathrm{G}_{\mathrm{w}}=\mathrm{G}_{\mathrm{w}}^{\mathrm{s}}+\mathrm{G}_{\mathrm{w}}^{\mathrm{o}} \\
& \max _{\mathbf{P}_{\mathrm{w}}} \mathbf{G}_{\mathrm{w}}=\left[\left(\mathbf{d}^{\max }-\frac{\beta_{1}\left(\mathbf{P}_{\mathrm{s}}-\mathbf{P}_{\mathbf{0}}\right)}{1-\rho}\right)\left(\mathbf{P}_{\mathrm{w}}-\mathbf{C}_{\mathbf{u}}\right)\right]+ \\
& {\left[\left(\frac{\beta_{2}\left(\rho \mathbf{P}_{s}-\mathbf{P}_{0}\right)}{\rho(1-\rho)}\right)\left(\mathbf{P}_{w}-\mathbf{C}_{u}\right)\right]}
\end{aligned}
$$


Berdasarkan jumlahan dari persamaan 3,4, dan 5, didapatkan keuntungan total DCSC $\left(\mathrm{G}_{\mathrm{T}}\right)$ seperti diberikan pada persamaan 6 .

$\max _{\mathrm{P}_{\mathrm{s}}, \mathrm{P}_{\mathrm{o}}, \mathrm{P}_{\mathrm{w}}} \mathrm{G}_{\mathrm{T}}=\mathrm{G}_{\mathrm{s}}+\mathrm{G}_{\mathrm{o}}+\mathrm{G}_{\mathrm{w}}$

Sebagai konsekuensi dari tersusunnya tiga fungsi objektif diatas, maka variabel keputusan dalam model ini adalah offline price (Ps), online price $\left(\mathrm{P}_{\mathrm{o}}\right)$ dan supplier price $\left(\mathrm{P}_{\mathrm{w}}\right)$. Beberapa constraint yang perlu disertakan untuk menjamin property penting dari DCSC terwakili di dalam model adalah sebagai berikut:

1. Harga jual di ketiga titik pengambilan keputusan $\mathrm{P}_{\mathrm{s}}, \mathrm{P}_{\mathrm{o}}$, dan $\mathrm{P}_{\mathrm{w}}$ harus memiliki profit margin secara vertikal, di mana $C^{u}$ adalah unit cost dari produk/jasa yang ditawarkan.

$\mathrm{P}_{\mathrm{s}}, \mathrm{P}_{\mathrm{o}}, \mathrm{P}_{\mathrm{w}} \geq C^{u}$

2. Interplay antar $\mathrm{P}_{\mathrm{s}}$ dan $\mathrm{P}_{\mathrm{o}}$ yang direpresentasikan oleh parameter utama dalam penelitian ini, yakni $\rho$. Secara umum, $\mathrm{P}_{\mathrm{o}}$ akan lebih rendah dibanding $\mathrm{P}_{\mathrm{s}}$ sebagai konsekuensi pengorbanan yang dilakukan oleh online customer dengan tidak adanya physical inspection maupun hilangnya excitement sebelum membeli.

$\mathrm{P}_{\mathrm{s}} \geq \frac{\mathrm{P}_{\mathrm{o}}}{\tilde{\mathrm{n}}}$

3. Batas minimum permintaan online demand,dengan $\mathrm{d}_{\mathrm{o}}^{\mathrm{l}}$ adalah proporsi permintaan relatif terhadap offline channel.

$\mathrm{d}_{\mathrm{o}}^{1} \mathrm{D}_{\mathrm{s}} \leq \mathrm{D}_{\mathrm{o}}$

\section{Hasil dan pembahasan}

Parameter sistem amatan yang diperlukan oleh model dalam penelitian ini yaitu $\rho, d^{\max }, \mathrm{P}_{\mathrm{sh}}$, $\mathrm{P}_{\text {oh }}, \mathrm{P}_{\mathrm{wh}}, \mathrm{C}_{\mathrm{u}} \beta_{1,}$ dan $\beta_{1}$. Sebagai catatan, $\mathrm{P}_{\mathrm{sh}}, \mathrm{P}_{\mathrm{oh}}, \mathrm{P}_{\mathrm{wh}}$ adalah rata-rata data historis harga jual dalam satu periode penjualan yang ditentukan oleh manajer offline dan online channel serta supplier secara berturut-turut. Rekapitulasi parameter yang dimaksud disajikan di Tabel 1 .

Nilai-nilai harga yang ditentukan secara intuitif oleh para manager DCSC di objek amatan $\left(\mathrm{P}_{\mathrm{sh}}, \mathrm{P}_{\mathrm{oh}}\right.$, dan $\left.\mathrm{P}_{\mathrm{wh}}\right)$ apabila disubstitusikan ke dalam fungsi objektif di persamaan 6 akan mengenerate nilai demand $\left(\mathrm{D}_{\mathrm{oh}}\right.$ dan $\left.\mathrm{D}_{\mathrm{wh}}\right)$ menghasilkan

Tabel 1. Parameter Sistem Amatan

\begin{tabular}{lccc}
\hline Parameter & Produk fashion & Smartphone & Ticket \\
\hline$\rho$ & 0,77 & 0,85 & 0,99 \\
$d^{\max }$ & 185 & 57 & 78 \\
$\mathrm{P}_{\mathrm{sh}}(\mathrm{Rp})$ & $366.764,25$ & $6.321 .488,37$ & $157.500,00$ \\
$\mathrm{P}_{\mathrm{oh}}(\mathrm{Rp}$ & $255.199,63$ & $6.247 .120,27$ & $150.000,00$ \\
$\mathrm{P}_{\mathrm{wh}}(\mathrm{Rp})$ & $245.723,54$ & $5.925 .355,81$ & $145.000,00$ \\
$\mathrm{C}_{\mathrm{u}}(\mathrm{Rp})$ & $235.723,54$ & $5.569 .122,62$ & $140.000,00$ \\
$\beta_{1}$ & 0,0001 & 0,000005 & 0,00003 \\
$\beta_{2}$ & 0,0002 & 0,00002 & 0,000055 \\
\hline
\end{tabular}

Tabel 2. Harga Jual Intuitif Tiap Channel Tanpa Proses Optimasi Beserta Nilai Demand dan Profitnya

\begin{tabular}{lccc}
\hline \multicolumn{1}{c}{ Variabel/Fungsi } & Produk fashion & Smartphone & Ticket \\
\hline Psh $(\mathrm{Rp})$ & $366.764,25$ & $6.821 .488,37$ & $177.500,00$ \\
Poh $(\mathrm{Rp})$ & $255.199,63$ & $5.727 .120,27$ & $170.000,00$ \\
Pwh(Rp) & $245.723,54$ & $5.655 .355,81$ & $155.000,00$ \\
Dsh & 136 & 21 & 56 \\
Doh & 31 & 11 & 32 \\
Gsh $(\mathrm{Rp})$ & $16.521 .287,52$ & $23.930 .280,12$ & $1.248 .750,00$ \\
Goh $(\mathrm{Rp})$ & $291.172,72$ & $800.889,62$ & $477.083,33$ \\
Gwh $(\mathrm{Rp})$ & $1.672 .207,38$ & $2.731 .957,05$ & $1.309 .583,33$ \\
GTh $(\mathrm{Rp})$ & $18.484 .667,62$ & $27.463 .126,79$ & $3.035 .416,67$ \\
\hline
\end{tabular}


nilai keuntungan tanpa proses optimasi $\left(\mathrm{G}_{\mathrm{sh}}, \mathrm{G}_{\mathrm{oh}}\right.$, $\mathrm{G}_{\mathrm{wh}}, \mathrm{G}_{\mathrm{Th}}$ ) seperti ditunjukkan di Tabel 2.

Selain itu, sebagai usulan pembanding, berdasarkan nilai-nilai parameter set selain $\mathrm{P}_{\text {sh }}$, $\mathrm{P}_{\mathrm{oh}}$, dan $\mathrm{P}_{\text {wh }}$ yang dikumpulkan yang terangkum di Tabel 1, dilakukan proses optimasi terhadap fungsi objektif yang ditunjukkan di persamaan 6 . Selain itu, constraints yang ada di persamaan 7, 8, dan 9 juga disertakan dalam perhitungan. Hasil optimasi yang didapat dengan memanfaatkan perangkat lunak Matlab memakai perintah fmincon diberikan di Tabel 3.

Berdasarkan perbandingan hasil percobaan numerik yang dilakukan terhadap 2 setting kondisi, yakni kondisi tanpa proses optimasi (intuitif) dan kondisi dengan proses optimasi, dapat disimpulkan bahwa:

1. Mekanisme penentuan harga DCSC dengan memanfaatkan parameter penerimaan pelanggan terhadap online channel yang diusulkan pada penelitian ini telah mampu merepresentasikan perilaku demand interplay baik untuk online dan offline channel.

2. Mekanisme ini juga mampu memberikan perbaikan kinerja finansial DCSC dengan bukti adanya peningkatan keuntungan supply chain secara keseluruhan. Angka peningkatan yang didapat dari parameter set yang dipilih adalah berturut-turut $11 \%, 17 \%$ dan $39 \%$ untuk produk fashion, smartphone dan ticket.

3. Di dalam distribusi keuntungan antar channel, dapat dilihat sebuah pola bahwa mekanisme usulan ini mengarahkan pada pengurangan keuntungan supplier $\left(\mathrm{G}_{\mathrm{w}}\right)$ dan peningkatan keuntungan di kedua belah outlet channel, yakni online dan offline. Dari kedua outlet penjualan ini, peningkatan keuntungan yang lebih besar (167\%-229\%) dinikmati oleh online channel dibandingkan keuntungan milik offline channel (17-35\%).

4. Meskipun demikian, mekanisme usulan ini akan diterima oleh kedua belah channel dikarenakan kedua belah pihak mengalami kenaikan performansi finansial yang positif. Hal ini menunjukkan kriteria "win-win solution" yang terpenuhi.

Ekstensi setting kondisi terhadap kondisi awal yang diwakili oleh parameter set awal seperti yang ditunjukkan di Tabel 1 perlu dilakukan untuk memperluas efektivitas mekanisme penetapan harga yang diusulkan. Terdapat 8 nilai parameter yang didapat dari objek amatan, meskipun demikian berdasarkan rangkaian penelitian sebelumnya diketahui bahwa parameter penerimaan pelanggan terhadap online channel $(\rho)$ adalah parameter yang paling signifikan. Hal ini mengakibatkan perlunya pengamatan lebih jauh tentang pengaruh parameter ini terhadap mekanisme penetapan harga yang diusulkan di penelitian ini.

Langkah sistematis yang dilakukan adalah melakukan analisis sensitivitas keuntungan DCSC dalam hal ini diwakili oleh notasi $\mathrm{G}_{\mathrm{T}}$ terhadap perubahan nilai parameter $\rho$. Dengan menaikkan dan menurunkan nilai $\rho$ sampai beberapa satuan unit, didapatkan perubahan keuntungan seperti yang ditunjukkan oleh Gambar 2. Analisis sensitivitas yang dilakukan memberikan spectrum

Tabel 3. Harga Jual Tiap Channel Hasil Proses Optimasi Beserta Nilai Demand Dan Profit

\begin{tabular}{lccc}
\hline \multicolumn{1}{c}{ Variabel/Fungsi } & Produk fashion & Smartphone & Ticket \\
\hline $\mathrm{P}_{\mathrm{s}}(\mathrm{Rp})$ & $378.764,25$ & $7.022 .631,46$ & $190.000,00$ \\
$\mathrm{P}_{\mathrm{o}}(\mathrm{Rp})$ & $270.132,70$ & $5.927 .321,45$ & $178.000,00$ \\
$\mathrm{P}_{\mathrm{w}}(\mathrm{Rp})$ & $238.132,70$ & $5.595 .462,68$ & $150.000,00$ \\
$\mathrm{D}_{\mathrm{s}}$ & 138 & 20 & 42 \\
$\mathrm{D}_{\mathrm{o}}$ & 24 & 7 & 56 \\
$\mathrm{G}_{\mathrm{s}}(\mathrm{Rp})$ & $19.374 .652,73$ & $29.242 .212,10$ & $1.680 .000,00$ \\
$\mathrm{G}_{\mathrm{o}}(\mathrm{Rp})$ & $777.532,15$ & $2.181 .954,03$ & $1.571 .111,11$ \\
$\mathrm{G}_{\mathrm{w}}(\mathrm{Rp})$ & $390.444,78$ & $712.883,56$ & $981.111,11$ \\
$\mathrm{G}_{\mathrm{T}}(\mathrm{Rp})$ & $20.542 .629,66$ & $32.137 .049,68$ & $4.232 .222,22$ \\
\hline
\end{tabular}




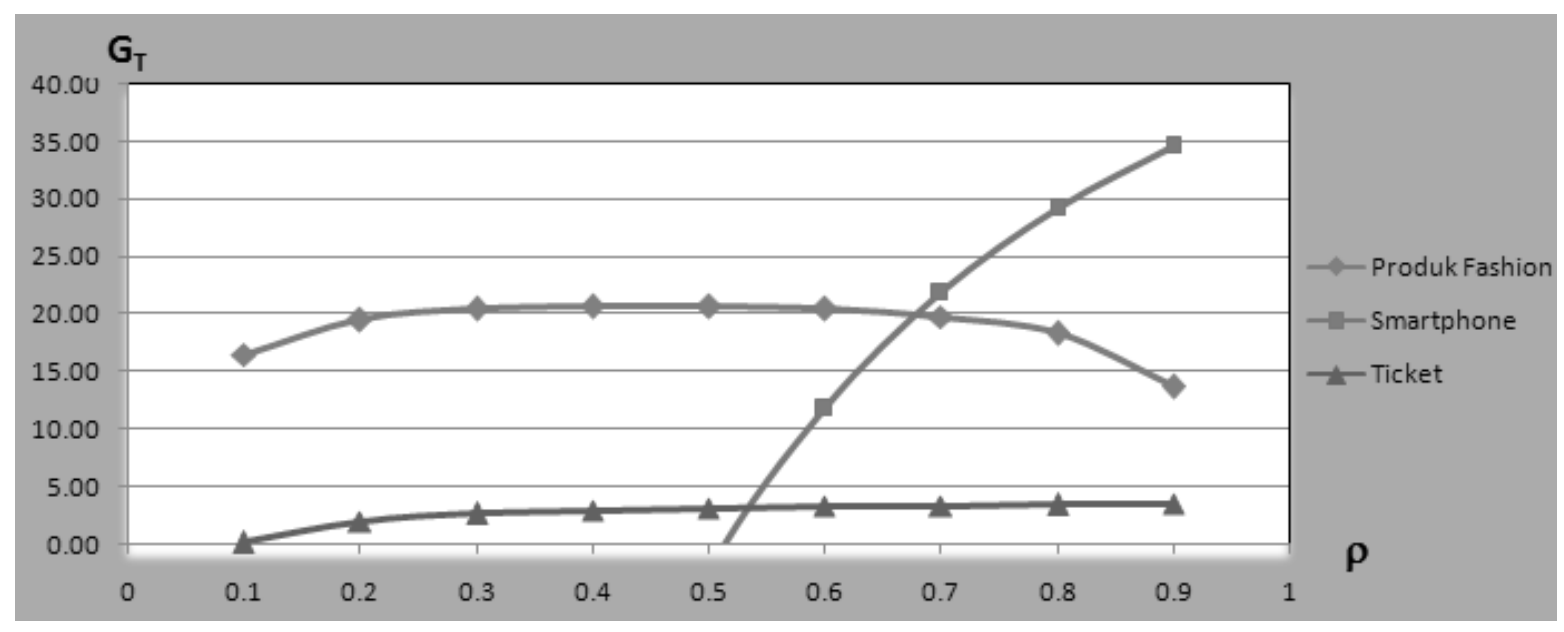

Gambar 2. Analisis Sensitivitas Keuntungan Supply Chain $\left(\mathrm{G}_{\mathrm{T}}\right)$ dalam Jutaan Rupiah terhadap $\rho$

nilai parameter penerimaan pelanggan terhadap online channel $(\rho)$ dalam kaitannya dengan perubahan keuntungan, untuk ketiga produk yang dipilih sebagai objek amatan di penelitian ini.

Beberapa hal penting yang didapat sebagai new insights dari analisis sensitivitas ini adalah:

1. Dalam rentang $0<\rho<1$, terlihat bahwa produk fashion yang memiliki nilai $\rho$ dasar hasil pengumpulan data terendah $(0,77)$ dibandingkan dengan produk yang lain (smartphone $=0,85$ dan ticket $=0,99$ ) memiliki kurva modal yang lebih lengkap dibanding produk yang lain.

2. Hal ini mengindikasikan bahwa terdapat nilai global optimum untuk maksimasi keuntungan supply chain pada sebuah nilai $\rho$ tertentu. Pada penelitian ini nilai optimum tersebut ada di kisaran penerimaan pelanggan online antara 0,4 dan 0,5 atau dapat diperkirakan dengan $\rho \approx 0,45$.

3. Implikasi praktisnya adalah manajemen DCSC akan menikmati keuntungan supply chain terbaik apabila pelanggan memiliki persepsi yang moderate (ada di kisaran 0,45, tidak terlalu rendah juga tidak terlalu tinggi dalam rentang 0 sampai 1 ) terhadap channel online relatif terhadap channel offline.

4. Produk smartphone memiliki tingkat sensitivitas keuntungan terhadap $\rho$ yang paling tinggi dibanding 2 produk yang lain (ticket dan produk fashion). Hal ini mengindikasikan bahwa kenaikan persepsi online customer sedikit saja, akan memberikan peningkatan potensi keuntungan yang multiplikatif dan signifikan kepada struktur supply chain secara keseluruhan. Untuk itu, pelaku bisnis DCSC untuk produk telekomunikasi ini seharusnya berusaha semaksimal mungkin meningkatkan persepsi online customer demi peningkatan profitabilitas bisnis mereka.

\section{SIMPULAN}

Penelitian ini mengajukan sebuah mekanisme penetapan harga untuk online dan offline channel dalam struktur Dual-Channel Supply Chain (DCSC). Kebutuhan akan adanya sebuah mekanisme penetapan harga ini bersifat penting dikarenakan adanya profit margin yang bersifat vertikal dan horizontal di dalam DCSC. Dengan memanfaatkan tingkat penerimaan pelanggan terhadap online channel relatif terhadap offline channel, sebuah pricing model untuk DCSC sebagai sebuah mekanisme usulan untuk menggantikan cara tradisional yang cenderung intuitif ditawarkan sebagai hasil dari penelitian ini. Berdasarkan pengumpulan data dari 3 macam produk sebagai objek amatan DCSC yang mewakili 3 level penerimaan pelanggan yakni high, medium dan low, serangkaian percobaan numerik yang dilakukan. Hasil yang didapat adalah untuk semua kelompok produk, mekanisme penetapan harga usulan mampu memberikan performansi finansial yang lebih baik dibanding cara non-prosedural yang cenderung 
intuitif. Selain itu, dari analisis suplemen untuk keperluan menguji sensitivitas dependent variable yang diamati, yakni keuntungan DCSC, didapatkan practical insight tentang optimum property untuk spectrum penerimaan pelanggan tiap produk yang diamati. Beberapa alternatif pengembangan dapat dipilih sebagai kelanjutan dari penelitian ini. Pemanfaatan fungsi yang lebih komprehensif, bukan lagi hanya sebatas sebuah nilai parameter untuk memodelkan dinamika dari penerimaan pelanggan terhadap online channel dapat dijadikan sebuah alternatif yang cukup menarik dari sisi pengembangan model. Selain itu, penambahan beberapa jenis produk diduga dapat menambah kelengkapan spektrum data yang diinginkan. Lebih jauh, hasil utama dari penelitian ini dapat dijadikan sebagai sebuah pondasi pengembangan model DCSC yang terkait dengan koordinasi antar channel, terkhusus untuk memberikan justifikasi seberapa berbeda seharusnya harga online dan offline harus ditentukan.

\section{DAFTAR PUSTAKA}

Anonim. Indonesian Internet Users. Tersedia di www. apjii.or.id.

Bernstein, F., 2008. "Bricks-and-Mortar" vs. "Clicksand-Mortar": An Equilibrium Analysis, European Journal of Operational Research, 187, 671-690.

Chu, Y., Fang, S.C., dan Wen, U.P., 2013. Pricing Policies for Substitutable Products in a Supply Chain with Internet and Traditional Channels, European Journal of Operational Research, 224, 542-551.

Dumrongsiri, A., Fan, M. E., Jain, A., dan Moinzadeh, K., 2008. A Supply Chain Model with Direct and Retail Channels, European Journal of Operational Research, 187, 691-718.
Gabrielsson, M., Kirpalani, V.H.M., dan Luostarinen, R., 2002. Multiple Channel Strategies in the European Personal Computer Industry, Journal of International Marketing, 10 (3), 73-95.

Liu, Y., Sun, Y., dan Hu, J.. 2013, Channel Selection in E-Commerce Age: A Strategic Analysis of Coop Advertising Models, Journal of Industrial Engineering and Management, 6 (1), 89-103.

Mahar, S., Bretthauer, K.M, dan Venkataramanan, M.A., 2009. The Value of Virtual Pooling in Dual Sales Channel Supply Chains, European Journal of Operational Research, 192 (2), 561-575.

Mols, N.P., 2000. Dual-Channels of Distribution: A Transaction Cost Analysis and Propositions, International Review of Retail, Distribution \& Consumer Research, 10 (3), 227-246.

Setyowati, M.R., 2012. Prospek Belanja "Online". Tersedia diwww.tekno.kompas.com.

Steinfield, C., Bouwman, H. and Adelaar, T., 2002. The Dynamics of Click-and-Mortar Electronic Commerce: Opportunities and Management Strategies, International Journal of Electronic Commerce, 7 (1), 93-119.

Takahashi, K., Aoi, T., Hirotani, D, dan Morikawa K., 2011. Inventory Control in a Two-Echelon DualChannel Supply Chain with Setup of Production and Delivery, International Journal of Production Economics, 133 (1), 403-415.

Widodo, E., Takahashi, K, and Morikawa, K., 2011. Managing Sales Return in Dual Sales Channel: Its Product Substitution and Return Channel Analysis. International Journal of Industrial and Systems Engineering, 9 (2), 121-149.

Xu, H., Liu, Z.Z, and Zhang, S.H., 2012. A Strategic Analysis of Dual-Channel Supply Chain Design with Price and Delivery Lead Time Consideration, International Journal of Production Economic, 139, 654-663.

Yan, R., 2008. Profit Sharing and Firm Performance in the Manufacturer-Retailer Dual-Channel Supply Chain, Electronic Commerce Research, 8 (3), 155-172. 